\title{
Pengembangan Bandicam Berbasis Power Point Sebagai Media Pembelajaran Seni Rupa PGSD
}

\author{
Ridha Sarwono \\ ridhoundaris@gmail.com \\ Universitas Darul Ulum Islamic Centre Sudirman GUPPI, Ungaran
}

\begin{abstract}
Development of Power Point Based Bandicam Learning Media in PGSD Fine Arts Course
\end{abstract}
\begin{abstract}
This study aims to develop a Power point-based Bandicam learning media in the fine arts subject for Elementary School Teacher Education at Darul Ulum University Islamic Center Sudirman. This study adapts the development model according to (Borg, W, R. \& Gall, 1983) as well as (Sukmadinata, 2007) which includes three stages, namely (1) the preliminary study stage, (2) the product draft preparation stage and (3) the development stage. and evaluation In assessing validity involves two validators, namely material expert validator, media expert validator, and one language validator. The subjects of this study involved 10 elementary school teacher education students at the Darul Ulum Islamic Center Sudirman University as a practical test. For data collection using a questionnaire. The results of this study indicate that the media that the author has developed is stated to be very valid and very practical to use in fine arts courses. With an average validation of $90 \%$ with a very valid category, and an average practical of 86.75 with a very practical category.
\end{abstract}

Keywords: Learning Media, Bandicam, Fine Arts

$\begin{array}{lcc}\text { Article Info } & \\ \text { Received date: } 15 \text { Desember } 2021 & \text { Revised date: } 5 \text { Januari } 2022 \quad \text { Accepted date: } 27 \text { Januari } 2022\end{array}$

\section{PENDAHULUAN}

Pendidikan adalah hal yang penting dalam memberikan dan menularkan ilmu pengetahuan bagi mahasiswa. Pendidikan seni rupa merupakan salah satu matakuliah di Pendidikan Guru Sekolah Dasar di Universitas Darul Ulum Islamic Centre Sudirman. Matakuliah pendidikan seni rupa yang dipelajari mahasiswa PGSD merupakan mata kuliah yang bertujuan untuk melatih kreativitas, keterampilan dan pengembangan pengetahuan bagi mahasiswa.

Dikatakan pendidikan akan tercapai apabila dalam tujuan pembelajaran serta materi dapat tersampaikan dengan baik sehingga mahasiswa mudah memahami materi. Perkembangan teknologi saat ini dapat mendukung tercapainya keberhasilan kegiatan pembelajaran apabila dapat memanfaatkannya. Bagi seorang Pengajar harus memilikiketerampilan dan kemampuan dalam menggunakan teknologi. Seorang pengajar dituntut dapat memberikan pembelajaran yang inovatif, sehingga mahamahasiswa secara mandiri dapat memaksimalkan ilmu pengetahuan yang mereka pelajarai dengan maksimal.

Dengan teknologi dimungkinkan dapat menjadi pendukung dalam proses belajar mengajar. Teknologi merupakan media yang dapat meningkatkan tercapainya sebuah pembelajaran. Menurut (A.H Hujair Sanaky, 2009) media atau alat yang memiliki fungsi menyampaikan pesan dalam pembelajaran serta membantu mahasiswa berkmomunikasi dengan pengajar. Salah satu yang dapat difungsikan dalam teknologi adalah sebagai sarana media pembelajaran. Dalam memahami materi mahasiswa memiliki gaya belajar yang berbeda-beda, sehingga sebagai pengajar harus senantiasa berpikir inovatif dalam memilih media yang cocok untuk digunakan dalam kegiatan belajar.

Berdasarkan data yang diperoleh dari observasi yang dilakukan ketika kegiatan Program Pengalaman Lapangan (PPL) masih ada pengajar yang tidak menggunakan media pembelajaran dalam pembelajaran seni rupa, kalaupun ada media pembelajarannya masih bersifat manual belum menggunakan teknologi. Sebagai pengajar tentunya dituntut untuk dpat memilih media yang tepat bagi mahasiswa agar materi yang disamp[aikan dapat mudah dipahami.

Dengan teknologi dapat menyatukan file berupa teks, gambar dan audio menjadi sebuah media yang baik dalam mengakomudir macam-macam gaya belajar yang dimiliki oleh mahasiswa. Media 
pembelajaran yang inovatif serta interaktif dapat membantu pengajar dalam menyajikan atau menyampaikan materi, membantu mahasiswa dalam meningkatkan pemahaman materi yang dipelajarai, sehingga mahasiswa termotivasi dan bersemangat dalam kegiatan pembelajaran matakuliah seni rupa.

Bandicam berbasis power point merupakan salah satu media penunjang dalam kegiatan belajar mengajar. Menurut Rusman (Indriyanti, 2017) Power point merupakan media yang terdapat di program windows yang sangat menarik dan dapat dikembangkan sebagai media interaktif yang dapat dipergunakan untuk membantu kegiatan pembelajaran. (Herayanti, L., Safitri, B. R., Sukroyanti, B. A., \& Putrayadi, 2019) mengatakan bahwa bandicam merupakan program yang dapat merekam aktivitas layar laptop ataupun PC. Penggabungan antara powerpoint dan bandicam menjadi media pembelajaran yang menarik dan bisa untuk disimpan, dimanan mahasiswa dapat mengulang materi kapanpun dan dimana saja, sehingga dapat membantu mahasiswa dalam belajar mandiri.

Sumiati dan Asra, 2007, Media pembelajaran merupakan sarana atau alat penyampai pesan yang dapat memberikan manfaat dan fungsi yang luas, memberikan fungsi untuk memperjelas materi yang akan disampaiakan, memberi pengalaman yang nyata, mahasiswa dapat berinteraksi, materi dapat dipelajari secara berulang-ulang, mempersempit keterbatasan ruang dan waktu, karena dengan media pembelajaran semua materi dapat dirangkum dalam satu media.

Berdasarkan dari penjelasan diatas, maka penelitian ini mempunyai tujuan mengembangkan media pembelajaran dengan program bandicam yang berbasis power point pada matakuliah seni rupa mahasiswa PGSD Universitas Darul Ulum Islamic Centre Sudirman untuk mempermudah mahasiswa memahami materi yang terdapat pada media.

Pandemi covid-19 yang terjadi di Indonesia saat ini sangat mempengaruhi proses belajar mengajar di semua lembaga pendidikan, baik dari pendidikan dasar sampai pendidikan tinggi semua terkena dampaknya. Media pembelajaran yang inovatif menjadi salah satu jalan bagi berlangsungnya pembelajaran mahasiswa PGSD Universitas Darul Ulum Islamic Centre Sudirman. Permasalahan yang terjadi menjadi pemikiran bersama-sama, sehingga peneliti melakukan penelitian dengan judul Pengembangan Media Pembelajaran Bandicam berbasis Power Point pada matakuliah seni rupa mahasiswa PGSD Universitas Darul Ulum Islamic Centre Sudirman.

\section{KAJIAN PUSTAKA}

Penelitian yang dilakukan oleh (Novitri Angraini, 2021) dalam penelitian tersebut mengembangan media Bandicam sebagai media pembelajaran pada mata pelajaran Prakarya dan Kewirausahan di SMK dengan tingkat keberhasilan media pembelajaran masuk pada kategori sangat valid dengan skor $92.60 \%$, serta kategori sangat praktis pada ujicoba siswa dengan skor 87.15\%. Sehingga media pembelajaran Bandicam layak untuk digunakan dalam pembelajaran mata pelajaran Prakarya dan Kewirausahaan.

Media pembelajaran sebagai sarana penyampaian informasi saat ini berkembang sangat pesat, banyak jenis-jenis media pembelajaran di buat dan digunakan sebagai saran penyampaian materi di lembaga pendidikan. Dari tahun ke tahun perkembangan media dari yang manual sampai yang menggunakan tekknologi karena diimbangi dengan berkembangnya model-model pembelajaran. Kebutuhan akan media pembelajaran yang inovatif, efektif dan juga efesien sangatlah dibutuhkan dalam lingkungan lembaga pendidikan tidak terlepas pada perguruan tinggi. Kebutuhan mahasiswa akan pembelajaran yang efektifan dan efesien dalam proses belajar mengajar, membuat pengajar untuk selalu menciptakan media pembelajaran sesuai dengan proses kegiatan pembelajaran agar tujuan pembelajaran tersampaikan secara maksimal pada mahasiswa secara maksimal. Dalam kegiatan pembelajaran sebaiknya menggunakan media pembelajaran yang sesuai dengan kebutuhan dan karakter mahasiswa agar pembelajaran bisa tersampaikan secara maksimal.

Pengembangan merupakan rancangan yang dihasilkan untuk meningkatkan kualitas serta mutu yang lebih baik. Lebih jelas lagi dikatakan bahwa (Sumarno, n.d.) pengembangan adalah proses membuat suatu rancangan kedalam bentuk fisik yang nyata dan merupakan sebuah perubahan yang inovatif, sehingga dalam merancang pengembangan media perlu disesuaikan dengan masalah dan kebutuhan penggunanya.

Bandicam adalah software yang digunakan untuk merekam kegiatan di layar dekstop dengan kualitas yang tinggi dan hasil yang maksimal. Aplikasi bandicam akan merekam semua kegiatan di 
layar dekstop dengan kualitas video yang tinggi. Aplikasi Bandicam merupakan utilitas perekam layar yang sangat mudah penggunaannya. Bandicam memiliki fitur utama, seperti: overlay, kamera web, yang memfasilitasi penggunaan kamera web saat sedang merekam. Hasil videonya terlihat figur pengajar. Bandicam dapat mencampurkan file suara saat video sedang direkam serta menambahkan efek klik dan animasi.

Microsoft Power Point merupakan pengembangan dari microsoft dalam program komputer yang khusus untuk presentasi. Microsoft Power Point dikembangkan oleh Bob Gaskin dan Dennis Austin sebagai presentator bernama Forethought, Inc yang kemudian menjadi Power Point. Power point memiliki fitur-fitur animasi yang mendukung dalam pembelajaran serta fitur-fitur yang ada diharapkan dapat membantu mengembangkan media pembelajaran yang inovatif. Saat pembelajaran diperlukan tampilan power point sehingga memungkinkan mahasiswa tertarik dahulu mengenai apa yang sedang diajarakan oleh pengajar (Erlina, 2009), Powerpoint membantu dalam menyajikan serta memperjelas materi yang disampaikan serta kegiatan yang variatif membuat suasana yang tidak membosankan. Mahasiswa akan lebih termotivasi untuk memahami materi yang disampaikan.

Seni rupa merupakan cabang seni yang bisa ditangkap oleh indera mata dan tangan. Seni rupa mengolah konsep-konsep dasar seni antara lain; garis, bidang, bentuk, volume, warna, dan tekstur, yang mengacu pada nilai estetika. Cabang seni yang mengutamakan ekspresi ide atau konsep sang seniman menjadi bentuk yang dapat menstimulasi indra penglihatan (Herawati Ida Siti, 1999) Senada dengan pendapat tersebut, menurut (Sachari, 2002) ungkapan dari pengalaman artistik maupun ideologis yang menggunakan warna dan garis untuk mengungkapkan perasaan, mengekspresikan emosi, gerak, ilusi maupun ilustrasi dari kondisi subjektif seseorang.

\section{METODE PENELITIAN}

Prosedur pengembangan dalam penelitian mengadaptasi model pengembangan menurut (Borg, W,R. \& Gall, 1983) dan juga (Sukmadinata, 2007). Prosedur yang diadapsi tersebut meliputi tiga tahap yaitu (1) tahap studi pendahuluan, (2) tahap penyusunan draft produk dan (3) tahap pengembangan dan evaluasi.

Pada tahap studi kepustakaan, peneliti melakukan kajian terhadap konsep-konsep atau teoriteori yang berkenaan dengan media pembelajaran, Bandicam serta Powerpoint. Kajian juga dilakukan terhadap kurikulum khususnya matapelajaran Seni Rupa. Berdasarkan pada studi kepustakan mengenai dasar-dasar teori dan konsep serta survai lapangan, maka peneliti menyusun draft awal produk yaitu media pembelajaran bandicam berbasis powerpoint yang akan dikembangkan. Draft produk yang telah dihasilkan kemudian diujicoba kepada mahasiswa. Tahap pengembangan dan evaluasi dengan melakukan uji coba yang bertujuan untuk menyempurnakan media pembelajaran dengan mempraktekkan secara langsung di lapangan.

Pengembangan media pembelajaran Bandicam berbasis powerpoint yang digunakan sampai dengan tahap pengembangan dilakukan melalui alur: validator ahli yaitu, media, materi, dan bahasa. Subjek uji coba lapangan melibatkan dari 3 mahasiswa ujicoba terbatas, 10 orang mahasiswa ujicoba luas.

\section{HASIL PENELITIAN}

Hasil dari validasi melalui ahli media pembelajaran dan ahli materi dengan melakukan dua kali validasi sebelum ujicoba dan sesudah ujicoba dilihat dari aspek 1) Aspek Daya Tarik; 2) Aspek Kemudahan Dipahami; 3) Aspek Efisiensi Waktu dan 4) Aspek Manfaat dapat dilihat pada tabel 1 dibawah ini.

Tabel 1. Hasil Validasi Para Ahli dan Bahasa

\begin{tabular}{|c|c|c|c|c|c|}
\hline No & Penilaian & Jumlah Item & Jumlah & Nilai Validasi & Kategori \\
\hline 1. & Materi & 12 & 100 & $92 \%$ & Sangat Valid \\
\hline 2. & Media & 10 & 49 & $90 \%$ & Sangat Valid \\
\hline 3. & Bahasa & 5 & 21 & $88 \%$ & Sangat Valid \\
\hline & \multicolumn{3}{|c|}{ Nilai Rata-Rata } & $90 \%$ & Sangat Valid \\
\hline
\end{tabular}

Dari tabel 1 diatas berdasarkan empat aspek menunjukan bahwa Hasil validasi Ahli Materi, memiliki nilai rata-rata 92\% dengan kategori Sangat Valid. Hasil validasi Ahli Media menunjukkan 
skor 90\% dengan kategori Sangat Valid, dari segi bahasa memiliki skor 88\% dengan kategori Valid. Sedanghkan hasil dari ahli materi dan ahli media berdasarkan penilaian mahasiswa tentang media pembelajaran bandicam berbasis Powert Point memiliki skor rata-rata 90\% dengan kategori Sangat Valid.

Tabel.2 Hasil Praktikalitas Mahasiswa

\begin{tabular}{|c|c|c|c|}
\hline Aspek & No. Pernyataan & Skor & Ketegori \\
\hline \multirow[t]{5}{*}{ 1. Daya Tarik } & 2 & 88 & \multirow[t]{6}{*}{ Sangat Praktis } \\
\hline & 3 & 86 & \\
\hline & 4 & 76 & \\
\hline & 7 & 82 & \\
\hline & 12 & 88 & \\
\hline Skor Rata-rata & & 84 & \\
\hline \multirow{3}{*}{ 2. Kemudahan Dipahami } & 1 & 86 & \multirow[t]{4}{*}{ Sangat Praktis } \\
\hline & 8 & 88 & \\
\hline & 9 & 90 & \\
\hline Skor Rata-rata & & 88 & \\
\hline 3. Efisiensi Waktu & 5 & 86 & \multirow[t]{2}{*}{ Sangat Praktis } \\
\hline Skor Rata-rata & & 86 & \\
\hline \multirow[t]{3}{*}{ 4. Manfaat } & 6 & 90 & \multirow[t]{4}{*}{ Sangat Praktis } \\
\hline & 10 & 84 & \\
\hline & 11 & 89 & \\
\hline Skor Rata-rata & & 87.6 & \\
\hline \multicolumn{2}{|c|}{ Total Skor Rata-rata } & 86.75 & Sangat Praktis \\
\hline
\end{tabular}

Dari tabel 2 diatas dapat dilihat bahwa 1) Aspek Daya Tarik memiliki skor 84 dengan kategori Sangat Praktis 2) Aspek Kemudahan Dipahamin memiliki skor 88 dengan kategori Sangat Praktis, 3) Aspek Efisiensi Waktu memiliki skor 86 dengan kategori Sangat Praktis 4) Aspek Manfaat memiliki skor 87.6 dengan kategori Sangat Praktis, Total skor rata-rata dari ke empat aspek adalah 86.75.

Sedangkan Untuk hasil uji kepraktisan media pembelajaran diketahui melalui angket yang diisi oleh mahasiswa. Hasil uji coba kepraktisan dari mahasiswa jumlah rata-rata memiliki skor 87.6 dengan kategori Sangat Praktis.

\section{PEMBAHASAN}

Mengacu pada salah satu hasil penelitian tentang pengembangan media pembelajaran Bandicam pada mata pelajaran prakarya dan kewirausahaan, dapat dilihat bahwa tingkat keberhasilan dari pengembangan media pembelajaran tersebut memiliki kategori sangat praktis, artinya bahwa pengembangan media tersebut memiliki tingkat keberhasilan mudah dalam pemakaian dan dapat serta layak dipergunakan pada mata pelajaran prakarya dan kewirausahaan. (Novitri Angraini, 2021)

Sedangkan hasil tingkat keberhasilan penelitian yang peneliti lakukan, dapat dilihat dari hasil ujicoba berdasarkan Praktikalitas Mahasiswa dengan beberapa aspek; (1) Aspek Daya tarik, setelah diujicoba memberikan efek ketertarikan bagi mahasiswa untuk menggunakan, (2) Aspek Kemudahan dipahami, setelah diujicoba mahasiswa lebih memahami materi, (3) Aspek Efesiensi waktu, setelah ujicoba penggunaan bandicam tidak terlalu banyak waktu yang terbuang, (4) Aspek Manfaat, setelah ujicoba mahasiswa memiliki pengalaman yang baru dalam bidang teknologi dan pengembangan media pembelajaran.

Hasil penilaian dari pakar ahli media, materi dan ujicoba pada mahasiswa dapat disimpulkan bahwa pengembangan mediapembelajaran bandicam berbasis power point dalam matakuliah seni rupa PGSD Universitas Darul Ulum Islamic Centre Sudirman memiliki kategori sangat praktis, sehingga penelitian ini dapat digunakan untuk mendukung proses pembelajaran matakuliah seni rupa di PGSD.

\section{SIMPULAN DAN SARAN}

Hasil dari penelitian pengembangan media pembelajaran Bandicam berbasis Powerpoint yang peneliti lakukan berdasarkan validasi ahli media dan materi, ujicoba terbatas serta ujicoba luas dapat 
disimpulkan bahwa; 1) Media yang dikembangkan pada pembelajaran matakuliah seni rupa PGSD Universitas Darul Ulum Islamic Centre Sudirman dapat dinyatakan valid untuk dipergunakan. 2) Media pembelajaran pada matakuliah seni rupa PGSD Universitas Darul Ulum Islamic Centre Sudirman dinyatakan sangat praktis dan mudah digunakan.

Penulis menyarankan agar penggunaan media disesuaikan dengan pembelajaran dan mata pelajarannya. Media pembelajaran bandicam berbasis power point dapat digunakan pada matakuliah seni rupa dapat digunakan bagi pengajar mahasiswa PGSD Universitas Darul Ulum Islamic Centre Sudirman. Agar media pembelajaran Bandicam berbasis poserpoint ini dapat meningkatkan pembelajaran tentang seni rupa dan dapat dikembangkan lagi agar lebih sempurna. Mahasiswa diharapkan lebih kritis dalam mengikuti pembelajaran seni rupa saat menggunakan media pembelajaran tersebut.

\section{UCAPAN TERIMAKASIH}

Ucapan terimakasih kepada semua mahasiswa Pendidikan Guru Sekolah Dasar - UNDARIS cohort 2020 yang telah berpartisipasi dalam penelitian ini serta semua pihak-pihak yang telah berpartisipasi dalam penelitian ini.

\section{DAFTAR PUSTAKA}

A.H Hujair Sanaky. (2009). Media Pembelajaran. Safiria Insania Press.

Borg, W,R. \& Gall, M. . (1983). Education Research : An Introduction. Longman.

Erlina. (2009). Supermedia Panduan Praktis Memanfaatkan Media Mengajar Dari Internet. Erlangga.

Herawati Ida Siti, I. (1999). Pendidikan seni rupa. Dikti.

Herayanti, L., Safitri, B. R., Sukroyanti, B. A., \& Putrayadi, W. (2019). Pelatihan pembuatan video pembelajaran bagi guru-guru di SDN 1 Ubung dengan memanfaatkan bandicam. Jurnal Pendidikan Dan Pengabdian Masyarakat.

Indriyanti, R. (2017). Pengembangan Media Pembelajaran Powerpoint Interaktif Materi Penyesuaian Makhluk Hidup Terhadap Lingkungan untuk Mahasiswa Kelas V SD Negeri Depok 1.

Novitri Angraini. (2021). Pengembangan Media Pembelajaran Bandicam Berbasis Power Point Dalam Pembelajaran Prakarya Dan Kewirausahaan Kelas X Di Sma Pembangunan Laboratorium UNP. Universitas Negeri Padang.

Sachari, A. (2002). Estetika: Makna, Simbol dan Daya. ITB.

Sukmadinata, N. S. (2007). Metode Penelitian Pendidikan. Rosdakarya.

Sumarno, A. (n.d.). Penelitian Kausalitas Komparatif. elearningunesa.

Sumiati dan Asra. (2007). Metode Pembelajaran (CV. Wahana Prima (ed.)). 